\title{
Sexually Transmitted Diseases at Monkey Bay Community Hospital in Mangochi, Malawi; an Analysis of Characteristics of Common Sexually Transmitted Diseases
}

\author{
David S. Chung1,2, Min Jung Koh²,3, Sung Hwan Chough4, Seog In Moon², Gene K. Lee', Ivy Kim², \\ Yujin Kim², Jae Hee Kim², Lorie Kim², Hyunjin Kim², Eunice Kang², Fatsani Manase5, \\ Thomas Nyirenda ${ }^{2,5^{*}}$
}

\author{
${ }^{1}$ School of Medicine, University of Virginia, Charlottesville, VA, USA \\ ${ }^{2}$ Youth with Talents, Fairfax, VA, USA \\ ${ }^{3}$ School of Medicine, Georgetwon University, Washington DC, USA \\ ${ }^{4}$ College of Dentistry, NYU, New York, NY, USA \\ ${ }^{5}$ Clinical Research Education and Management Service, Lilongwe, Malawi \\ Email: paulschung08@gmail.com
}

How to cite this paper: Chung, D.S., Koh, M.J., Chough, S.H., Moon, S.I., Lee, G.K., Kim, I., Kim, Y., Kim, J.H., Kim, L., Kim, H., Kang, E., Manase, F. and Nyirenda, T. (2020) Sexually Transmitted Diseases at Monkey Bay Community Hospital in Mangochi, Malawi; an Analysis of Characteristics of Common Sexually Transmitted Diseases. Advances in Infectious Diseases, 10, 243-252.

https://doi.org/10.4236/aid.2020.105022

Received: April 16, 2020

Accepted: December 26, 2020

Published: December 29, 2020

Copyright ( 2020 by author(s) and Scientific Research Publishing Inc. This work is licensed under the Creative Commons Attribution International License (CC BY 4.0).

http://creativecommons.org/licenses/by/4.0/

\begin{abstract}
We present the characteristics of the commonly diagnosed sexually transmitted infections (STI) at a clinic of Monkey Bay community hospital by a retrospective study. We conducted an audit of patients' hospital records from a STIs clinic at Monkey Bay community hospital in Mangochi District (Malawi) covering a period from January 2019 to June 2019 (18 months). Data was tabulated in excel and analyses were made based on sex, age, male circumcision status, pregnancy and the pattern of STIs diagnosed within the chosen study period. A total number of 659 clients presented at STI clinic of Monkey Bay community hospital between January 2018 and June 2019. Out these clients, $409(62 \%)$ were females and 250 (38\%) were males. Most of the patients were in the age range of 25 years or above $(447,68 \%)$. Majority of the patients were HIV negative (523, 79\%). Out of the 250 males, 113 (45\%) were circumcised. Among female patients 56 of the 409 (14\%) were pregnant. The most common presentations for all cases put together were lower abdominal pain $(253,38 \%)$, then urethral discharge $(189,29 \%)$, abnormal vaginal discharge $(141,21 \%)$, genital ulcer disease $(64,10 \%)$, in that order. Syphilis, genital warts, inguinal bubo and scrotal swelling were less common. The most common presentation in males was urethral discharge $(178,71 \%)$, while in females it was lower abdominal pain (214, 52\%). Our audit showed that in Mangochi (Malawi) sexually transmitted diseases of various types are more
\end{abstract}


common among young adults, females and uncircumcised men. There was no much difference in the percentage of STI's between HIV positive and HIV negative people. These results point to an alarmingly high level of risky sexual behaviors among sexually active age groups in this part of Malawi, a country which still has one of the highest HIV prevalence in sub-Saharan Africa. This calls for continued and better research and control for transmission of STIs in the district.

\section{Keywords}

Sexually Transmitted Infections (STIs), Mangochi, Malawi

\section{Introduction}

Sexually transmitted diseases (STDs) are among the most frequently occurring infections worldwide. There are an estimated 376 million new infections yearly with one of the following Sexually Transmitted Infections (STIs): chlamydia, gonorrhea, syphilis and trichomoniasis [1] [2]. More than 500 million people are estimated to have genital infection with herpes simplex virus (HSV) and more than 290 million women are infected with human papilloma virus [3] [4]. Up to $80 \%$ of curable STIs occur in developing countries. Adolescents and young adults have the highest rates of these STIs [5].

In developing countries including, Malawi, STIs and their complications are among the top reasons why adults seek healthcare services [6] [7]. Among women of child-bearing age curable STIs account for a larger number of disability-adjusted life-years lost than any other group of diseases apart from maternity related disorder [8]. Sexually transmitted infections are a known risk factor for HIV transmission [8] [9] and figures released by UNAID (2001) [10] showed that HIV prevalence among male STI Patients in major urban areas of Malawi was as high as $54.8 \%$ and currently ranges from $37.7 \%$ to $70 \%$ [11].

In a study conducted in 2015 in Malawi, 15\% of women and 10\% of men aged 15 - 49 reported having an STI and/or its symptoms [12]. The majority of STIs have no symptoms or have only mild symptoms [13].

In developing countries like Malawi, laboratory diagnosis of every sexually transmitted infection is not feasible due to limited resources at clinic level. Due to this challenge Malawi adopted a syndromic approach to STI management in 1993 under the John Snow Incorporated/support to AIDS and Family Health (JSU-STAFH) project. The syndromic management implies an approach in which clinical algorithms, such as decision trees, for commonly presenting signs and symptoms (e.g. urethral discharge or genital ulcer) are used in case management [14].

Data from Malawi shows that algorithms for the diagnosis and treatment can be effective. Urethral discharge and genital ulcer disease in men had cure rates of $87 \%-99 \%$ and $68 \%$ - $98 \%$ respectively. The sensitivities for the algorithms for 
vaginal discharge ranged from $73 \%$ to $93 \%$ for index cases, and from $29 \%$ to $86 \%$ for contacts of index cases [15]. Effective syndromic management of STIs requires recognition of common and consistent combinations of signs and symptoms of STIs, knowledge of the most common causative organisms for the various syndromes, knowledge of the socio-behavioral characteristics of people with STDs as well as knowledge of health-seeking behavior of STIs patients [16]. In Malawi, most of these data are from urban settings. We conducted a clinical audit with an aim of assessing characteristics of sexually transmitted diseases among clients presenting at one of rural hospitals in Malawi (Monkey Bay Hospital in Mangochi).

\section{Methods and Materials}

\subsection{Setting}

The study was done in STI clinic at Monkey Bay community hospital in Mangochi (Malawi) which is a referral center to many other health centers and clinics in the district with close to 1 million inhabitants.

\subsection{Design}

\section{Selection Criteria}

Case records of all patients who attended the STIs clinic at the Monkey Bay community hospital in Mangochi, Malawi from January 2019 to June 2019 were retrieved, included in the study and studied. Data was entered into excel by sex, age, circumcision status, pregnancy status and the pattern of STIs syndromic diagnoses.

\subsection{Data Analysis}

Using excel frequency tables and graphs were generated using targeted variables of sex, age, circumcision status, pregnancy status and the pattern of STIs syndromic distribution. Only patient who presented with STIs related symptoms were considered for analysis.

\section{Results}

\subsection{Patient Characteristics}

Figures 1-3 and Figure 6 show the characteristics of 659 clients who presented at STI clinic of Monkey bay community hospital between January 2018, to June 2019. Out these clients, 409 (62\%) were females and 250 (38\%) were males. Most of the patients were in the age range of 25 years or above $(447,68 \%)$, then 20 24 years $(149,23 \%)$ and $0-19$ years $(63,9 \%)$. Table 1 shows that majority of the patients were HIV negative (523, 79\%), 93 (14\%) were HIV positive and the remaining 43 (7\%) had unknown HIV status. Figure 6 shows that out of the 250 males, only 113 (45\%) were circumcised versus 137 (55\%) uncircumcised. In females 56 of the 409 (14\%) were pregnant versus 353 (86\%) non pregnant. 


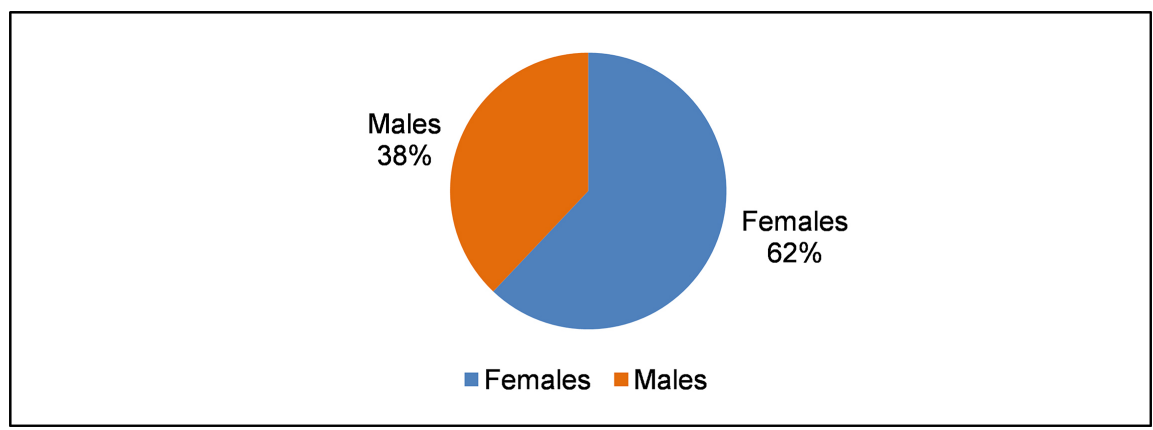

Figure 1. Percentage of clients by sex, $\mathrm{n}=659$.

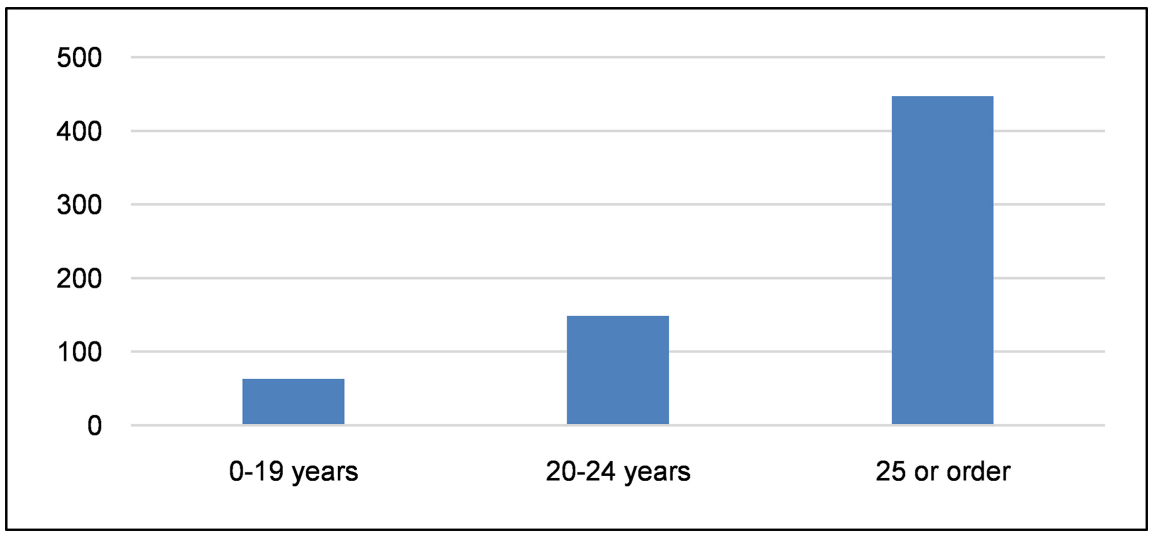

Figure 2. Age range of patient at STI clinic.

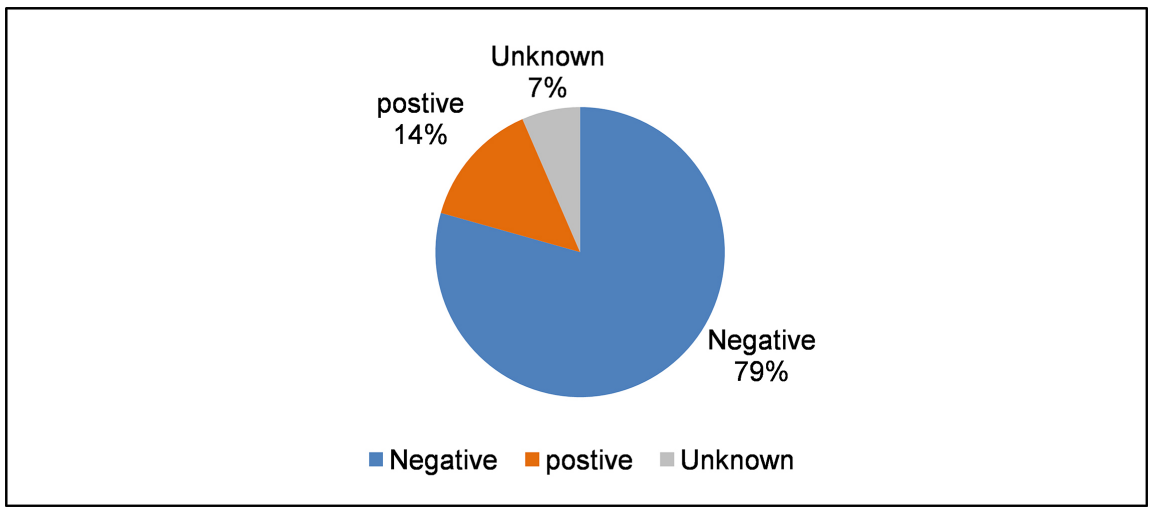

Figure 3. HIV status.

\subsection{Distribution of Diagnosed STIs Conditions}

Figure 4 shows the distribution of the conditions of diagnosed using the syndromic approach as; Lower abdominal pain (LAP), urethral discharge (UD), abnormal vaginal discharge (AVD), genital ulcer disease (GUD), syphilis (VDRL+), scrotal swelling (SS), genital warts (GW) and inguinal bubo (BU).

The most common presentations were LAP (253, 38\%), then UD (189, 29\%), AVD (141, 21\%), GUD (64, 10\%), and others in that order. No case of balanitis was registered over the period of 18 month. The most common presentation in males was urethral discharge $(178,71 \%)$, while in females it was lower abdomin- 
al pain $(214,52 \%)$.

\subsection{Comparison by Circumcision Status}

Figure 5 shows the number of STI's were higher in non-circumcised male (marked as MNC in the chart) as compared to circumcised male (marked as MC in the chart) group. For example, genital ulcer disease was 1.5 times higher in non-circumcised men than in circumcised men.

\subsection{Comparison by Age Group}

Figure 6 shows that STI's were much more common in patients aged 25 or above. For example, lower abdominal pain and urethral discharge were at least three times more common in age range of 25 or above than in $20-24$ age group.

\subsection{Comparison by HIV Status}

Table 1 shows that there was no clear difference in STI presentations between HIV positive and HIV negative patients (see Table 1).

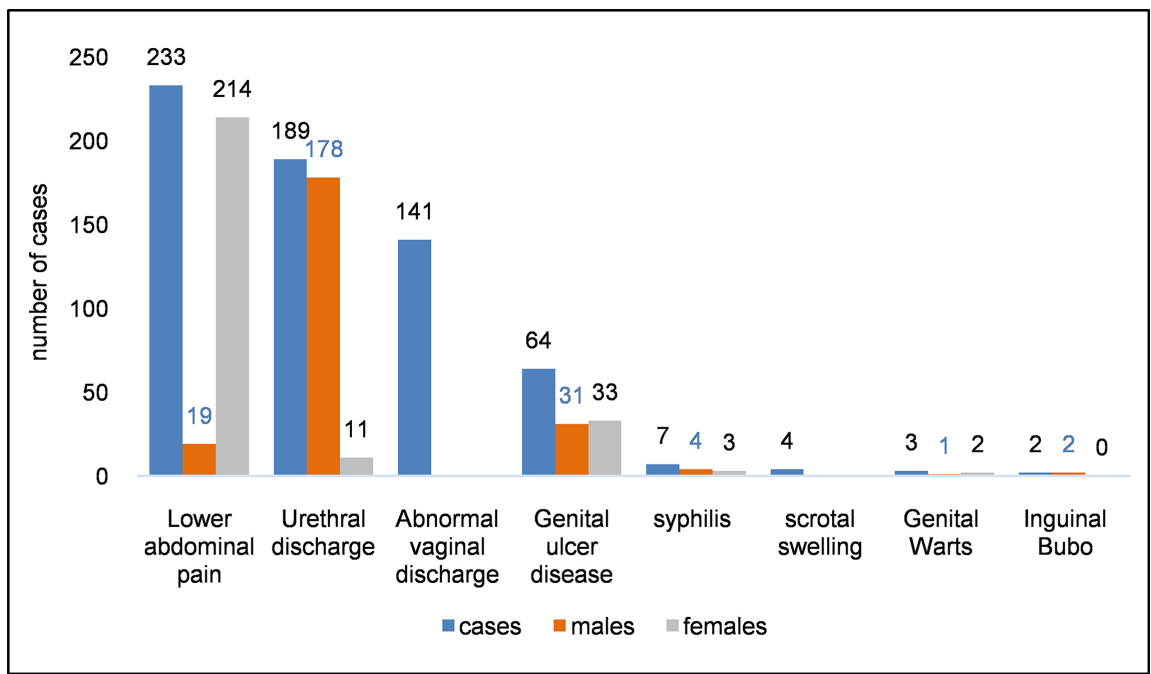

Figure 4. Common STI presentation at the clinic by sex.

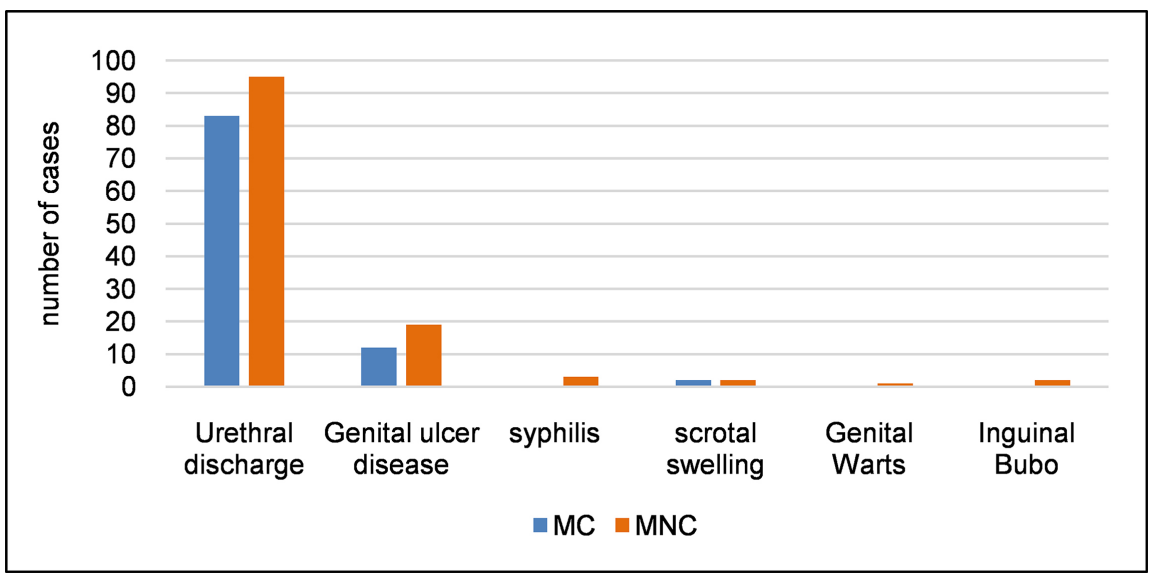

Figure 5. Comparison of STI's in male by circumcision status. 


\subsection{Seasonal Variations in STI's}

Figure 7 shows that there was slight month-to-month variation in the number of patients presenting to the STI clinic. In from January to December of 2018, the monthly range of patients seen was between 19 and 81 .

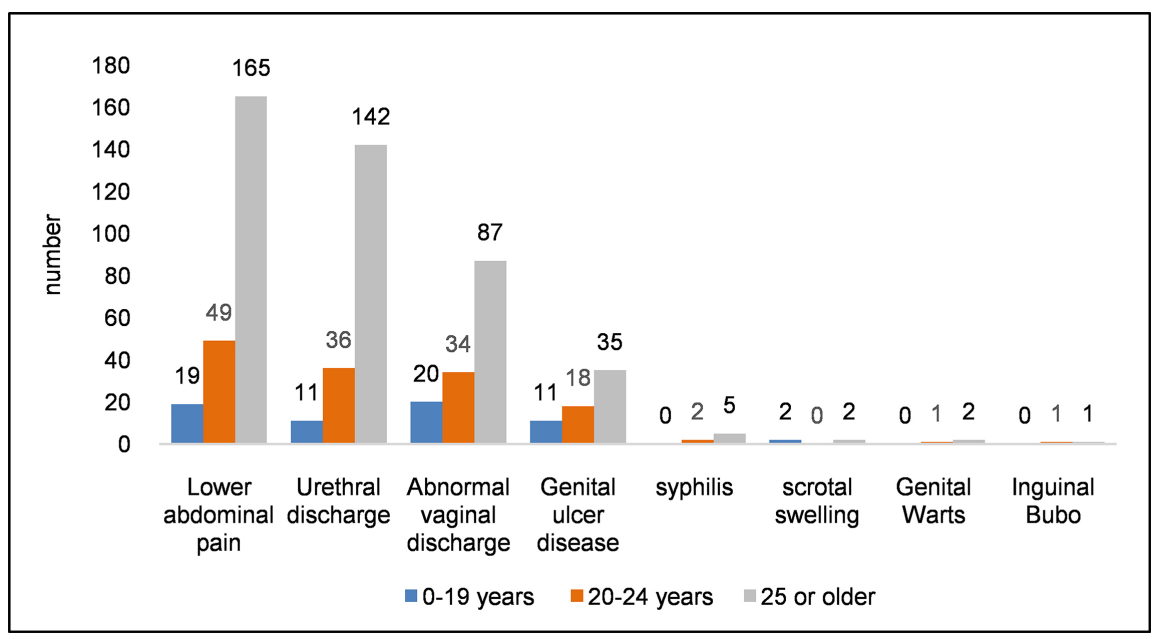

Figure 6. Comparison of STI's by age group.

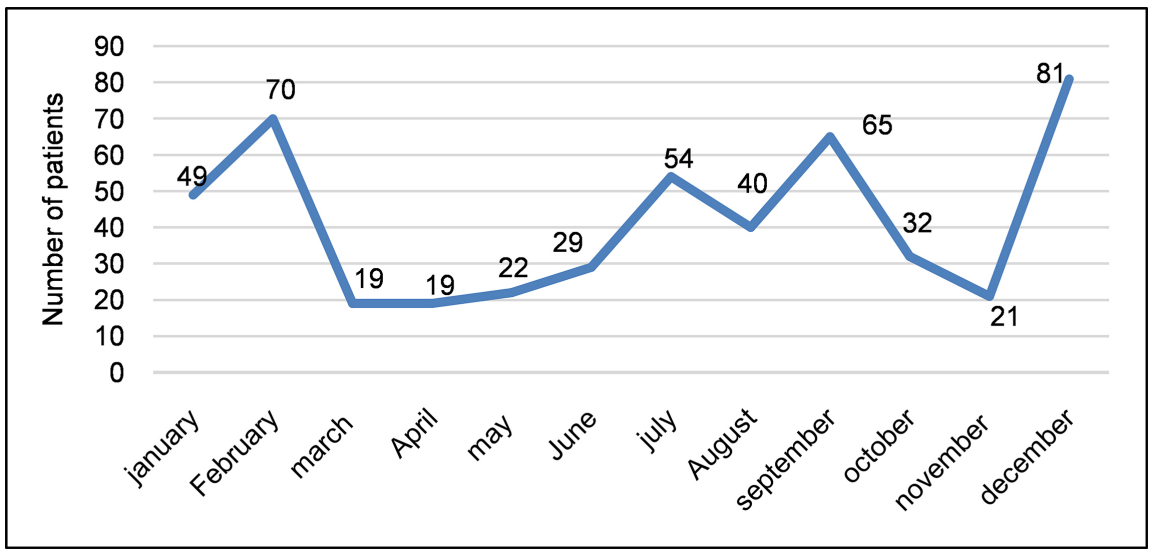

Figure 7. Trend of STI's by month in 2018.

Table 1. Percentage of STI's in HIV positive and Negative people.

\begin{tabular}{ccc}
\hline Conditions & Percentage in HIV+ & Percentage in HIV- \\
\hline Lower abdominal pain & 34 & 35 \\
Urethral discharge & 17.2 & 31 \\
Abnormal vaginal discharge & 22 & 22 \\
Genital ulcer disease & 11 & 9.3 \\
syphilis & 2 & 1 \\
scrotal swelling & 1 & 1 \\
Genital Warts & 0.1 & 0.1 \\
Inguinal Bubo & 0 & 0.1 \\
\hline
\end{tabular}




\section{Discussion}

Our study shows that an STI clinic in rural Malawi attends to high burden of patients with STIs. The results of the present retrospective 18-month study at an STI clinic of Monkey Bay community hospital reveal that STIs are more prevalent among females. This finding is similar to the Malawi Demographic and Health Survey (DHS) finding in 2016, where the percentage of females self-reporting STI symptoms was slightly higher (15\%) than in men (10\%) [12]. This shows that females in Malawi require interventions that will protect them from contracting STIs which also predisposes them to HIV infection. The difference between the numbers of male and female patients may also be attributed to the difference in health seeking behavior between males and female. An earlier study done in Mangochi reveals that 38.9\% females with STI symptom sought care from health profession as compared to $33.9 \%$ men [16]. More studies are required to explain such differences for designing interventions that can used to target both and women in the fight against STIs among them.

This audit also showed that a significant number of people presenting to the study clinic and were diagnosed with STI are aged 30 and below. Young adults are the sexually active age group and also bear a high burden of HIV and other STD's [17]. This emphasizes the importance of behavioral change messages that are used to the control of STD's and HIV in these age groups. In a study that was done in Nigeria, not seeking treatment was more prevalent among those aged 15 - 18 (44\%), as compared to the older age groups (68\%) [18]. This shows that age influences the distribution of the STIs seen in audits like we did in this study.

The prevalence of STIs in our study is similar to an urban study done at Queen Elizabeth Central Hospital, in Blantyre Malawi, where urethral discharge and genital ulcer disease were among the four common STDs [16].

Our audit showed that STIs were more common among uncircumcised men as compared to circumcised men, which is a similar to other studies done across Africa and the world. Circumcision has been shown to be associated with lower STI rates. Mehta SD et al. in his study reveals that male circumcision reduces genital ulcer disease (GUD) incidence with a risk ratio of 0.51 and 0.52 [19]. The risk for GUD is also shown to decreased in female partners of circumcised males as for Chlamydia trachomatis infection [20], bacterial vaginosis, and trichomonas infection as well [21]. Circumcision also reduces the risk of other sexually transmitted diseases like genital herpes, syphilis as well as human papilloma virus infection [22].

In our study lower abdominal pain, abnormal virginal discharge and Genital ulcer diseases (GUD) were the common presentations in females. Syphilis and genital warts were less common. This finding is also similar to other studies done in urban Blantyre [16]. Our audit also showed that STIs affected both pregnant and non-pregnant women.

In our study there was not much difference in STI's among HIV positive and HIV negative patients. This finding is different from other studies, which shows 
that HIV positive people are more likely to have STI's than HIV negative people [23]. Kristensen showed that that $62.4 \%$ of 705 unselected patients at an STD clinic in Lilongwe (Malawi) were HIV sero-positive [24]. Mbizvo et al. and Fehler et al. showed that in Zimbabwe and South Africa respectively, STD patients had a $67 \%$ risk for contracting HIV. [25] [26]. Our study could have showed a different HIV distribution because of inadequate sample size.

A last finding in this study was seasonal variations of STI's in 2018. More STI's were registered in the months of December and February. This is different from a study which was done in Blantyre [16], where the number of cases in December was low. This may be attributed to the Christmas cerebrations, when a lot of people come to Mangochi for cerebrations and holidays. Usually during this time there is a presumed of increased sexual activities, which may explain the high number of STI's. The higher number of STI clients in February may be due to shortage of foods and other resources during this time, which may force more women to engage into transactional sex, for money to cater for their day to day needs.

\section{Conclusions}

Our audit indicates that the majority of clients seeking care at Monkey bay community Hospital STI clinic were younger people in productive sexual age, predominantly females, most of which presented with lower abdominal pain. Circumcision was associated with lesser STIs. Pregnant and nonpregnant females are equally affected with STIs. While, there was no clear distinction in the percentages of STIs between HIV+ and HIV- clients. Conclusion of the effect of seasonality in the number cases of STI in Monkey Bay requires more definitive studies.

Our study had limitations. Firstly, as a cross sectional study, the conclusions only apply to the study period. Secondly, the sample size on which the conclusions are based is fixed such that much broader conclusions can be made in larger studies that our audit has stimulated.

\section{Acknowledgements}

The authors acknowledge the Youth with Talents for sponsoring this medical project (YWT-2019-06PH), the hospital in charge and all other health workers of Monkey bay community hospital who made this work to happen. Funding for the research was provided by Clinical Research Education and Management Services (CREAMS).

\section{Conflicts of Interest}

No conflicts of interest were declared in relation to this paper.

\section{References}

[1] Rowley, J., Vander Hoorn, S., Korenromp, E., Low, N., Unemo, M., Abu-Raddad, 
L.J., et al. (2019) Global and Regional Estimates of the Prevalence and Incidence of Four Curable Sexually Transmitted Infections in 2016. WHO Bulletin, 97, 548-562. https://www.who.int/bulletin/volumes/97/8/18-228486.pdf

[2] World Health Organization (2018) Report on Global Sexually Transmitted Infection Surveillance, 2018. World Health Organization, Geneva.

https://www.who.int/reproductivehealth/publications/stis-surveillance-2018/en/

[3] Looker, K.J., Magaret, A.S., Turner, K.M., Vickerman, P., Gottlieb, S.L. and Newman, L.M. (2015) Global Estimates of Prevalent and Incident Herpes Simplex Virus Type 2 Infections in 2012. PLOS ONE, 10, e114989.

https://journals.plos.org/plosone/article?id=10.1371/journal.pone.0114989 https://doi.org/10.1371/journal.pone.0114989

[4] de Sanjosé, S., Diaz, M., Castellsagué, X., Clifford, G., Bruni, L., Muñoz, N., et al. (2007) Worldwide Prevalence and Genotype Distribution of Cervical Human Papillomavirus DNA in Women with Normal Cytology: A Meta-Analysis. Lancet Infectious Diseases, 7, 453-459.

https://www.thelancet.com/journals/laninf/article/PIIS1473-3099(07)70158-5/fulltext https://doi.org/10.1016/S1473-3099(07)70158-5

[5] (2006) Disease Control Priorities in Developing Countries. 2nd Edition, Chapter 17, Sexually Transmitted Infections, The International Bank for Reconstruction and Development/The World Bank. Oxford University Press, New York. https://www.ncbi.nlm.nih.gov/books/NBK11734/

[6] Mayaud, P., Hawkes, S. and Mabey, D. (1998) Advances in Control of Sexually Transmitted Diseases in Developing Countries. Lancet, 351, S29-S32. https://doi.org/10.1016/S0140-6736(98)90009-5

[7] Concerted Action for the Syndromic Approach (CASA) (2002) Optimising the Use of the Syndromic Approach for STI Management and Prevention in Resource Poor Settings. International Literature Review, 9, 24.

[8] World-Bank (1993) World Development Report. Investing in Health. Oxford University Press, New York.

[9] Cohen, M.S. (1998) Sexually Transmitted Diseases Enhance HIV Transmission: No Longer a Hypothesis. Lancet, 351, S5-S7.

https://doi.org/10.1016/S0140-6736(98)90002-2

[10] Wasserheit, J.N. (1992) Epidemiological Synergy: Interrelationships between Human Immunodeficiency Virus Infection and Other Sexually Transmitted Infections. Sexually Transmitted Diseases, 19, 61-77. https://doi.org/10.1097/00007435-199219020-00001

[11] UNAIDS (2001) The HIV/AIDS Epidemic in Malawi. The Situation and the Response. UNAIDS Report, UNAIDS, Lilongwe.

[12] Harries, A.D., Nyirenda, T.E., Mphasa, N., et al. (2001) Screening for HIV Related Disease and Sexually Transmitted Infections in Patients with Tuberculosis in Malawi. Malawi Medical Journal, 13, 21-27.

[13] Mandiwa, C. and Namondwe, B. (2018) Factors Associated with Contraceptive Use among Young Women in Malawi: Analysis of the 2015-2016 Malawi Demographic and Health Survey Data. Contraception and Reproductive Medicine, 3, 1-8.

[14] Bosu, W.K. (1999) Syndromic Management of Sexually Transmitted Diseases: Is It Rational or Scientific? Tropical Medicine \& International Health, 4, 114-119. https://www.ncbi.nlm.nih.gov/pubmed/10206265

[15] Pettifor, A., Walsh, J., Wilkinson, D., et al. (2000) How Effective Is Syndromic Management of STDs: A Review of Current Studies. Sexually Transmitted Diseases, 
27, 371-385. https://doi.org/10.1097/00007435-200008000-00002

[16] Komolafe, I.O.O., Nkumba, J., Makoka, M.H., Makhalira, A. and Bonongwe, P. (2009) Sexually Transmitted Diseases at Queen Elizabeth Central Hospital, Blantyre, Malawi. East African Medical Journal, 77, No. 12.

[17] UNAIDS Report (2001) The HIV/AIDS Epidemic in Malawi. The Situation and Response UNAIDS Lilongwe.

[18] Mmari, K.N., Oseni, O. and Fatusi, A.O. (2010) STI Treatment-Seeking Behaviors among Youth in Nigeria: Are There Gender Differences. International Perspectives on Sexual and Reproductive Health, 36, 72-79.

https://www.researchgate.net/publication/45388709

[19] Mehta, S.D., Moses, S., Parker, C.B., Agot, K., Maclean, I. and Bailey, R.C. (2012) Circumcision Status and Incident Herpes Simplex Virus Type 2 Infection, Genital Ulcer Disease, and HIV Infection. AIDS, 26, 1141-1149. https://doi.org/10.1097/QAD.0b013e328352d116

[20] Castellsague, X., Peeling, R.W., Franceschi, S., de Sanjose, S., Smith, J.S., Albero, G., Diaz, M., Herrero, R., Munoz, N. and Bosch, F.X. (2005) Chlamydia trachomatis Infection in Female Partners of Circumcised and Uncircumcised Adult Men. American Journal of Epidemiology, 162, 907-916. https://doi.org/10.1093/aje/kwi284

[21] Gray, R.H., Kigozi, G., Serwadda, D., Makumbi, F., Nalugoda, F., Watya, S., Moulton, L., et al. (2009) The Effects of Male Circumcision on Female Partners' Genital Tract Symptoms and Vaginal Infections in a Randomized Trial in Rakai, Uganda. American Journal of Obstetrics \& Gynecology, 200, 42.E1-42.E7. https://doi.org/10.1016/j.ajog.2008.07.069

[22] Vella, M., Abrate, A., Argo, A. and Simonato, A. (2017) Circumcision and Sexually Transmitted Disease Prevention: Evidence and Reticence. In Fundamentals of Sexually Transmitted Infections, Chapter 8, 162-177.

[23] Taha, T.E., Dallabetta, G.A., Hoover, D.R., et al. (1998) Trends of HIV-1 and Sexually Transmitted Diseases among Pregnant and Post-Partum Women in Urban Malawi. AIDS, 12, 197-203. https://doi.org/10.1097/00002030-199802000-00010

[24] Kristensen, J.K. (1990) The Prevalence of Symptomatic Sexually Transmitted Diseases and Human Immunodeficiency Virus in Outpatients in Lilongwe, Malawi. Sexually Transmitted Infections, 66, 244-246. https://doi.org/10.1136/sti.66.4.244

[25] Mbizvo, M.T., Danso, A.P., Tswana S., Bassett, M., Marowa, E. and Moengeranwa, L. (1994) Reduced Semen Quality and Risky Behaviours amongst Men Consulting a Referral STD Clinic. Central African Journal of Medicine, 40, 294-299.

[26] Fehler, H.G., Lyall, M., Htun Ye, Muiznicks, S., Khoza, B.D. and Ballard, R.C. (1998) Genital Tract Infections among Women Attending an Urban Family Planning Clinic. Southern African Journal of Epidemiology and Infection, 13, 79-81. 